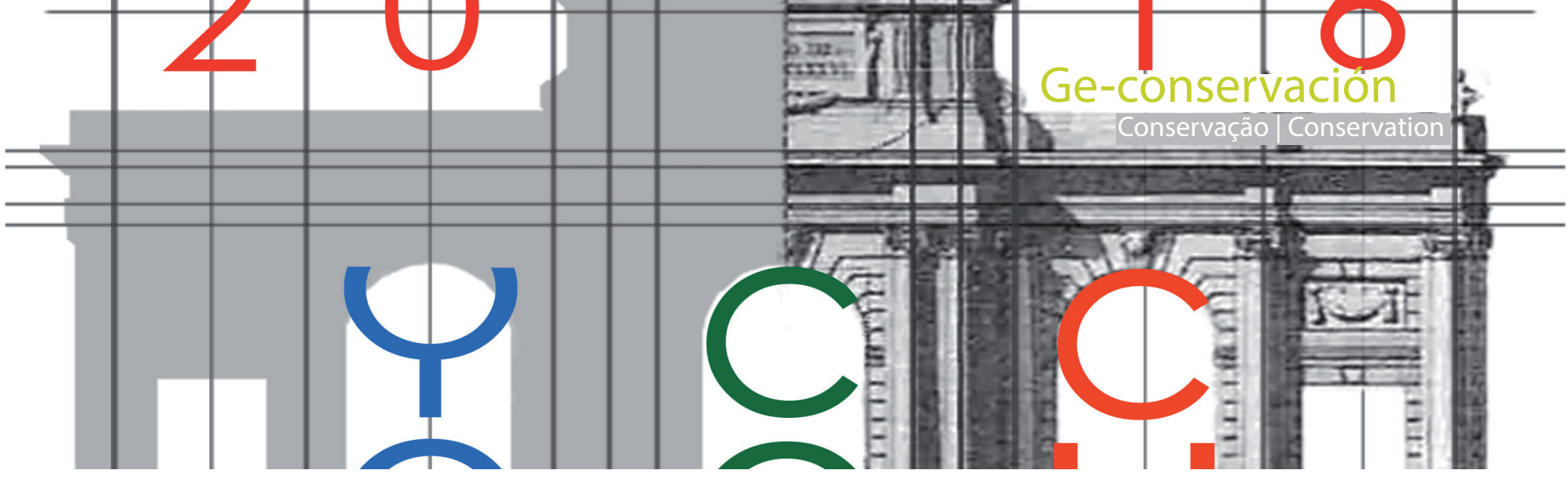

\title{
From the artwork to the "demo" artwork. Case Study on the conservation and degradation of new media artworks
}

\author{
Diego Mellado Martínez, Lino García Morales
}

\begin{abstract}
This paper describes the study case of the conservation of a new media artwork, Cannula, by Daniel Canogar (2016). This artwork combines and distorts videos downloaded from YouTube in order to create an oil-like live painting. Main new media conservation strategies are first introduced and discussed. Following, "re-creation" is presented as the best option to deal with the conservation of the elements that compose the artwork, such as its hardware -display, computer- and its software -custom made applications that combine and distort videos-. This paper focuses on a key element to the artwork that cannot be conserved by any of the exposed means: the Internet. YouTube is used to provide the videos to be used. If the service is not reachable -the connection is lost or YouTube is no longer available- the artwork will cease to exist as the artists conceived it. Storing in the memory of the computer the contents previously used provide a mean to re-use them if needed. In that case, the artwork will no longer be such -according to the artists, the live connection to the Internet defines the artwork- but a "demonstration". A self-documentation state defined as "demo", which, according to the authors, represents the closest possible experience to the original artwork.
\end{abstract}

Key words: New media art conservation, evolutionary conservation, re-creation, demo artwork, computer-based artwork conservation.

\section{De la obra de arte a la 'demo-obra de arte'. Caso de estudio en la conservación y degradación de obras de arte de nuevos medios}

Resumen: Este artículo muestra el caso de estudio de la conservación de una obra de arte de nuevos medios, Cannula, de Daniel Canogar (2016). Se comentan las principales estrategias para la conservación de arte de nuevos medios. Posteriormente, se presenta la "re-creación" como la mejor opción para lidiar con la conservación de los elementos que componen esta obra, tales como su hardware -pantalla, ordenador- como su software -una aplicación programadas que combinan y distorsionan videos - Pero este artículo quiere poner la atención en un elemento fundamental, que no puede ser conservado de ninguna de las maneras expuestas anteriormente: la Internet que proporciona los videos que la obra utilizará. Si esta conexión se pierde, la obra no puede existir tal y como el artista la concibió. Almacenar los contenidos previamente utilizados permitiría re-usarlos cuando no sea posible acceder a nuevos contenidos. En ese caso, la obra dejaría de ser tal y pasaría a ser una "demostración". Un estado de auto-documentación definida como "demo" que según los autores representaría la experiencia más cercana a la obra original posible.

Palabras clave: Conservación de arte de nuevos medios, conservación evolutiva, re-creación, obra demo, conservación de arte digital

\section{Introduction}

Cannula is a digital artwork based on the execution of custom software on a computer. The output of this program is presented in a LCD display. Both the code, developed under $\mathrm{C}++$ and the aesthetical characteristics of the display - frame width, resolution, size - are key factors of the artwork. The program uses those YouTube videos as a palette to create and abstract painting through an algorithm that, in real time, generates an abstract painting that is continuously changing and never repeating. The interaction with the artwork can be described as follows: the user/viewer inputs a search term (query) using a wireless keyboard. Then, the program looks for the YouTube's 100 most viewed videos matching that query and begins to download them. The moment the first video is downloaded, the previous images on LCD display are faded away and that first video is shown, distorted by the algorithm in such a way that resembles an oil-painting. As each of the following videos finish to download, they are added and combined to the composition (Figures 1 and 2). 


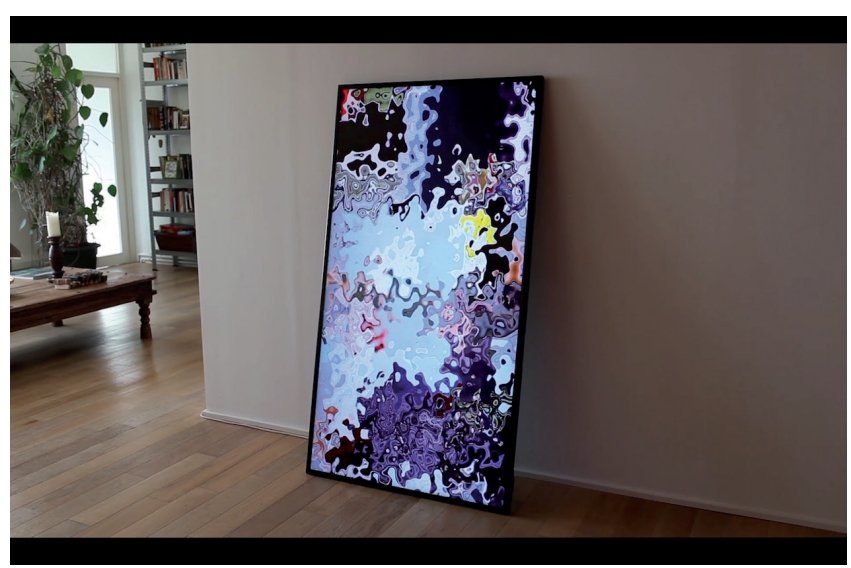

Figure 1.- Cannula, showing the original content used to created an abstract image (by the authors).

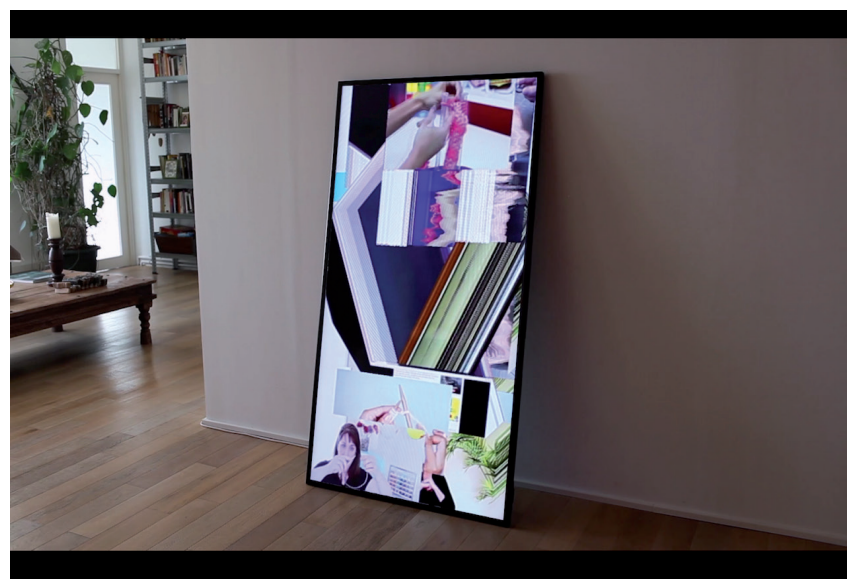

Figure 2.- Cannula, showing the resulting abstract image (by the authors).

The conservation of this kind of works has been commonly addressed using the main new media and digital art conservation strategies - storage or substitution, migration emulation or re-interpretation - but according to the authors, they are not enough (Mellado Martínez\& Garcia Morales, in press). The conservation of such a complex artwork must be considered from its very beginning -its production- in order to let the artwork "evolve" and change without modifying its nature. This is what "evolutionary conservation" means (Garcia 2016).

But this approach is not enough, at least for this particular case. The artworks is based on an online service - YouTube - whose continuity is not long term assured. Therefore, the loss of that service could jeopardize the integrity of the artwork. To avoid that loss, the contents used to generate the images -the sets of 100 videos downloaded after a query- are stored in the memory of the computer so they can be retrieved if the service is not available. Using previously downloaded contents do not represent the behavior conceived by the artist, although it is approved by him as a suitable alternative in case the service is downHence, the result cannot considered "the artwork". Instead, it can be understood as a demonstration of the artwork, a self-documentation on what the artwork was in a previous state that almost keeps the overall experience conceived by the artist.

It should be noted that one of the authors works in the Daniel Canogar's studio and assisted him as engineer in the whole process of production and preparation of the artwork for its future conservation. This allowed not only to obtain valuable information for this paper but, most important, to produce the artwork having in mind its future conservation

\section{Methods and Methodology}

New media artworks have become a conservation problem. Obsolescence and lack of resources can be named as part of the most difficult issues. Usually these problems are addressed as they happen, e.g. when component breaks down and a spare is needed or the software is running out of it expected behavior. What happens if one of those components, essential to the artwork, is no longer available? What happens if the artists did not have enough resources -e.g. time, money, knowledge- to present a final version of the artwork instead of a prototype? It is important to remember that "debugging" -i.e. a deep test of software looking for all its flaws- is a very resourceconsuming and high profile task. In the case of Cannula, this debugging took even more resources than those used to achieve a prototype or beta version-. This is not unusual, since all the possible states that the software could reach have to be foreseen and considered, for example, what happens if the connection is suddenly lost. Correctly defining all the possible states the software can run into and addressing how the program should behave represents a very expensive task, resources wise.

To overcome new media art conservation, four approaches have been typically considered (Rinehart and Ippolito, 2014):

\section{-Storage/Substitution}

It considers storing spares of the components of the artwork for the future. For example, if an artwork includes a projector, storing spare lamps could be an option. A more advance version of this approach is refreshment, where elements are refreshed prior to their failure.

The main problem of this approach is that it does not solve the problem, but postpones it. It does not overcome obsolescence-spares will spire out at some point too- and requires both logical and physical space for storage.

\section{-Migration}

Migration considers moving, "migrating" the content form 
an old media to a newer one in order to avoid obsolescence; for example, copying from VHS to DVD.

It could happen that, after several migrations, it becomes difficult to ensure that the quality of the content meets the required standards.

\section{-Emulation}

Emulation can be understood as a facsimile copy, where a new technology impersonates an old one. In a computer based artwork, for example, a modern computer with a new operative system (OS) could impersonate and old one, allowing an old piece software -based on an old OSto run on a newer machine without changing that old program in any way. The main problem in emulation is that the experience of the artwork in a new device may be jeopardized

\section{-Reinterpretation}

Reinterpret means to create the artwork again under a different point of view, sacrificing some aspects in order to maintain the original spirit; for example, a Renaissance picture reinterpreted by a contemporary artist. The main problem of reinterpretation is how to assure that the original spirit of the artist is kept, especially when he or she is no longer available.

An additional approach can be considered, what Garcia (2016) defined as "re-creation". This approach aims to create again -re-create- the artwork without changing its essence, its symbolic value -what Garcia defines as symbol-object- but using different components to the originals, therefore, changing its support -what Garcia defines as system-object-. These new components will behave in the same way -or most similar possiblethat the original. Somehow, it can be understood as a crossover between emulation and reinterpretation that allows the artwork to evolve in the future. Re-creation is a key element to understand what can be defined as "evolutionary conservation", this meaning an approach to conservation that allows the artwork "to change and evolve in order to stay the same" (Garcia 2016).

Evolutionary conservation is, according to the authors, a possible solution to new media art conservation problems. But it requires of a methodological approach in order the kept the artist intention. For example, it is necessary that the artists clearly state what defines both the systemobject and the symbol-object. These definitions will allow the re-creation of the artwork in the future.

In this case, the system-object is a combination of software -the set of rules that generates the artwork- and hardware -the physical devices that present the result of the software-. Both of them need to be defined by the artist in order to allow its future evolution. Describing hardware is not a trivial task: not only all the parts must be listed and their features clearly stated, but also it has to be considered how future parts could impersonate old ones. In this case and for the shake of simplicity of this paper, the hardware needs to be fulfilled in the future can be summarized as "the set of elements that allows the software to be executed at 30 frames per second, generating $1920 \times 1080$ pixel resolution output on a $75^{\prime \prime}$ display, in portrait mode".

According to the experience of the authors, it is software that presents the greater problem. For it to be able to "evolve", it has to be described in such an abstract way that could be easily understood and implemented by other means, for example, using a different programming language. This description must include, again, all the consideration of the artists that allows the system-object to generate the symbol-object. For example, in this case, video content has to be retrieved from YouTube. Therefore, it has to be pointed out that software has to download contents from that site and no other.

Figure 3 is an example of how the authors propose describing the software. This diagram -which in computer science jargon is known as a "flow diagram"- represents how the software works. A piece of software is usually composed of several sub-processes, also known as "threads". In this case, for illustrative proposes, figure 3 represents only the main thread.

As it has been commented before, there is a fundamental aspect for the artwork that presents serious conservation problems. Since the videos used to create the abstract image are to be taken from a specific online server -YouTube - and not other, what would happen if that service were not available? In that case, the artwork as defined would cease to exist.

As a way to overcome this problem, it was decided to store in the hard drive of the computer a copy of the most recently downloaded videos. Then, if the service is not available, the software could use that copy of the videos to generate again the output image, using the same algorithm used when YouTube was available, as it was recently downloaded. This stored content will not be documentation on the artwork but the ingredient for the artwork to create a "documentation output" of itself. In this case, the documentation will not be shown in a different medium as pictures or video taken from e.g. a performance. It will be the same system-object, providing an experience of the symbol-object difficult to distinguish from the original one.

It can be questioned if this scenario where the program uses previously downloaded videos can still be considered as the artwork. Therefore, the authors propose the term of "demo-artwork" to describe the new object. 


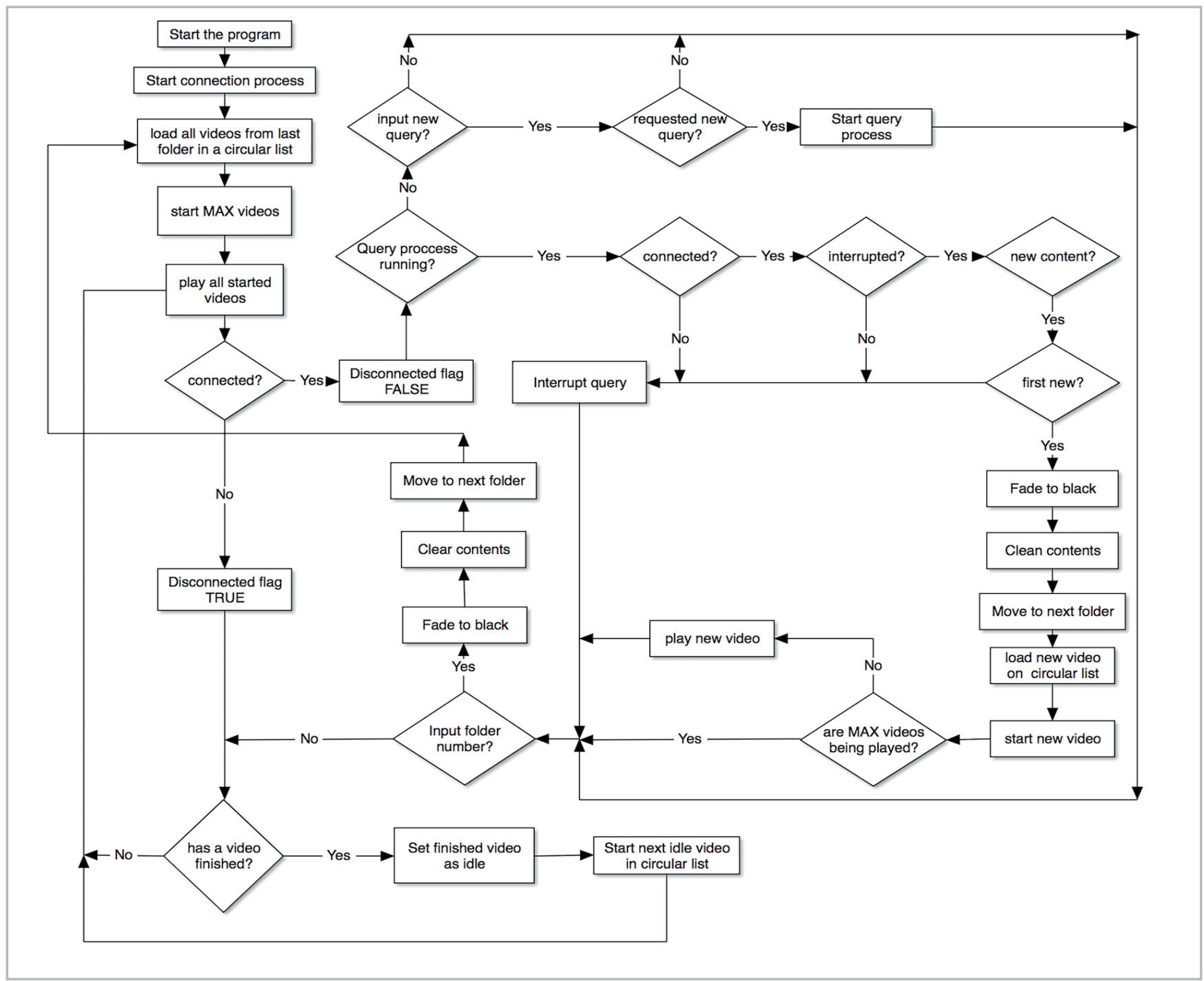

Figure 3.- Main process flow diagram (by the authors).

\section{Results and Discussion}

To allow future re-creation, all the previously shown considerations on hardware and software have to be presented and delivered. In this case, all are included in the manual of the artwork. For some time now, artist's studios have delivered manuals for their artworks which shown how to install the piece and how to turn it on and off. According to the authors, this is not enough. These manuals should include all the information needed to re-create the artwork, such as lists of parts, with its key features and flow diagrams for the software.

Gathering this information is not difficult when the conservation tasks are overcome from its very production, as in this case. When dealing with artworks already produced, these tasks, though not impossible, are harder to achieve. Classical restoration approach must always be kept on mind, but interviews with the producers of the artwork -in addition to the usual interviews to artists- and study of the source code of the artwork -which, according to the authors, must be delivered together with the artwork- should be part of the documentation gathered towards the artwork conservation. There will be cases when some -or all- of the information needed would be missing. In those cases, differences between recreation and reinterpretation may become blurry.

Still, a basic element, the access to YouTube, could fail. To avoid that, a demonstration mode is used. Immediately, a question arises: is this mode the actual artwork? The answer, according to the authors of this paper, is no. The artwork is defined as an interactive installation where users can request videos from YouTube in real live and that functionality is lost.

To overcome this problem, the authors propose the demo-mode, as degradation of the original artwork that would use videos requested in the past. This degraded version of the artwork can be seen as documentation of itself. 


\section{Conclusions}

The "evolutionary conservation" paradigm has been implemented during the production of a specific artwork, allowing for its future preservation and conservation with a recreation approach. This approach cannot be considered as a definitive solution but an additional tool for new media art conservation.

In addition, a novel mode has been implemented to avoid the complete loss of the artwork in case that the service in which it relies shut down, the "demo mode" as a degradation of the artwork. There has been a lot of discussion about documentation as a preservation tool (Scholte \& Wharton 2011) especially regarding performance documentation. Through a new approach, authors try to use the artwork interface to document the artwork itself. That documentation can be experienced through same interface of the actual artwork, even when the access to the resources needed to generate artwork is not available. In addition, that experience of the documentation is almost identical to the experience of the real artwork.

Finally, this paper wants to highlight the fact that producers and specially engineers should be taken into conservation teams. Not only for his or her deep knowledge of a technical matter -but for having developed what the art work calls new media. He or she is the ideal professional for restoration of these artworks.

\section{Bibliography}

CANOGAR, D. "Cannula", http://www.danielcanogar.com/ work/cannula [7-7-2016].

GARCIA MORALES, L., “Conservación Evolutiva. El tiempo... la dimensión que pasó", pp 5-8, http://www.academia. edu/8141968/CONSERVACI\%C3\%93N_EVOLUTIVA_EI_ tiempo_la_dimensi\%C3\%B3n_que_pas\%C3\%B3 [30-62016].

GARCIA MORALES, L., (2010). Conservación y restauración de arte digital (Tesis doctoral), pp 81-132 Universidad Europea de Madrid, Madrid.

GARCIA MORALES, L., "Recreación, una estrategia de conservación evolutiva" http://www.academia. edu/8092763/Recreaci\%C3\%B3n._Una_estrategia_de_ Conservaci\%C3\%B3n_Evolutiva_del_Arte_Digital [30-62016].

MELLADO MARTINEZ, D. and GARCIA MORALES, L., (In press). "Study Case on new media art conservation, evolution and degradation. From the artwork to the demo artwork". In: 5th International Conference Youth in Conservation of Cultural Heritage YOCOCU 2016 Congress Book. Madrid: MNCARS.
RINEHART R. and IPPOLITO J. (2014) Re-Collection: Art, New Media and Social Memory, Cambridge, The MIT Press. International Symposium Collecting and Conserving Performance Art, https://www.incca.org/events/internationalsymposium-\%E2\% $80 \% 9$ Ccollecting-and-conservingperformance-art\%E2\%80\%9D [5-07-2016].

SCHOLTE, T.; WHARTON, G. (2011).Inside Installations: Theory and Practice in the Care of Complex Artworks, pp 155-215 Amsterdam, Amsterdam University Press.

Openframeworks, http://openframeworks.cc [30-06-2016]. 


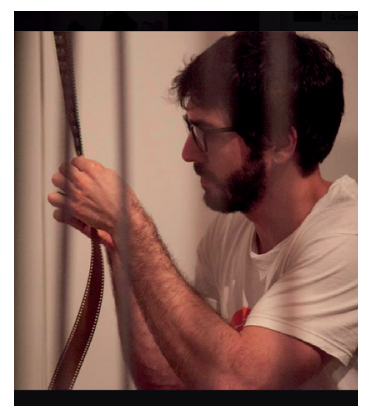

\section{Diego Mellado Martínez}

diego@helpmeimfamous.com

Diego Mellado is Engineer on Telecommunications by Universidad Carlos III de Madrid. He has designed and produced new media artworks for the last 7 years.

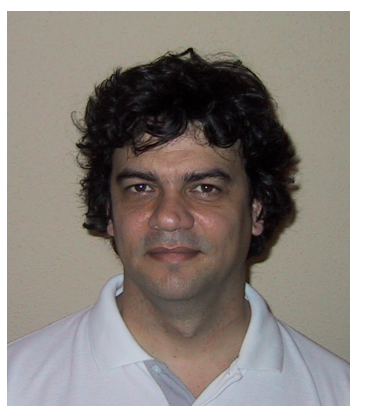

\section{Lino García Morales}

lino.garcia@upm.es

Lino García received a Ph.D. degree from Technical University of Madrid, Spain, in July 2006 and Ph.D. degree from European University of Madrid, Spain, in February 2011. 